\title{
Nursing consultation for people with diabetes mellitus: experience with an active methodology
}

\author{
Consulta de enfermagem às pessoas com Diabetes Mellitus: experiência com metodologia ativa
}

Consulta de enfermería a las personas con diabetes mellitus: experiencia con metodología activa

\author{
Silvana de Oliveira Silva', Letícia Martins Machado', Maria Denise Schimith", \\ Laís Mara Caetano da Silva", Vanessa do Nascimento Silveira", Anderson Cecchin de Bastos"I \\ 'Universidade Regional Integrada do Alto Uruguai e das Missões. Santiago, Rio Grande do Sul, Brazil. \\ "Universidade Federal de Santa Maria. Santa Maria, Rio Grande do Sul, Brazil. \\ III Prefeitura Municipal de Santiago. Santiago, Rio Grande do Sul, Brazil.
}

How to cite this article:

Silva SO, Machado LM, Schimith MD, Silva LMC, Silveira VN, Bastos AC. Nursing consultation for people with diabetes mellitus: experience with an active methodology. Rev Bras Enferm [Internet]. 2018;71(6):3101-8.

DOI: http://dx.doi.org/10.1590/0034-7167-2017-0611

Submission: 09-25-2017 Approval: 05-07-2018

\begin{abstract}
Objective: to describe our experience with a methodology for teaching nursing consultation in support of people with diabetes mellitus at a Family Health Unit. Method: experience report with four moments-submission of the proposal to the team; theorizing; nursing care for people with diabetes mellitus at home and at the health unit, and evaluation of learning. Results: the pedagogical process favored the integration between service and users, contributed to implement and apply the nursing process and strengthened professional training, based on the epidemiological profile of chronic diseases and its implications for nursing in primary care. Final considerations: the active methodology discussed here allowed for a resignification of knowledge and a qualification of nursing care, demonstrating to be an important instrument for integrating clinical practice and epidemiology in accordance to experienced reality. Descriptors: Nursing; Nursing Education; Problem-Based Learning; Chronic Diseases; Primary Health Care.
\end{abstract}

\section{RESUMO}

Objetivo: Descrever a experiência da utilização de metodologia da problematização para o ensino da Consulta de Enfermagem junto a pessoas com Diabetes Mellitus de uma Unidade de Saúde da Família. Método: Relato de experiência realizado em quatro momentos: apresentação da proposta à equipe, teorização, aplicação da sistematização da assistência de enfermagem às pessoas com diabetes mellitus no domicilio dos usuários e na Unidade de Saúde e avaliação da aprendizagem. Resultados: O processo ensino-aprendizagem favoreceu a integração do ensino com o serviço e usuários, contribuiu para a implantação e aplicação do processo de enfermagem e fortaleceu a formação a partir do reconhecimento do perfil epidemiológico para o cuidado de enfermagem às doenças crônicas na atenção primária. Considerações finais: A utilização da metodologia ativa propiciou a ressignificação do conhecimento e a qualificação do cuidado de enfermagem, constituindo-se como um importante instrumento para a união da clínica à epidemiologia a partir da realidade vivenciada.

Descritores: Enfermagem; Educação em Enfermagem; Aprendizagem Baseada em Problemas; Doenças Crônicas; Atenção Primária à Saúde.

\section{RESUMEN}

Objetivo: Describir la experiencia con la metodología de la problematización para la enseñanza de la consulta de enfermería a las personas con diabetes mellitus en una Unidad de Salud de la Familia. Método: Relato de experiencia realizado en cuatro momentos -presentar la propuesta al equipo; teorizar; dar asistencia de enfermería a las personas con diabetes mellitus en los domicilios y en la unidad de salud; $y$ evaluar el aprendizaje. Resultados: El proceso de enseñanza-aprendizaje favoreció la integración entre servicio y usuarios, contribuyó a implantar y aplicar el proceso de enfermería, y fortaleció la formación a partir del reconocimiento del perfil epidemiológico para el cuidado de enfermería a las enfermedades crónicas en la atención primaria. Consideraciones finales: 
La metodología activa propició la resignificación del conocimiento y la cualificación del cuidado de enfermería, constituyéndose como importante instrumento para unir la clínica a la epidemiología a partir de la realidad experimentada.

Descriptores: Enfermería; Educación en Enfermería; Aprendizaje Basado en Problemas; Enfermedad Crónica; Atención Primaria de Salud.

\section{INTRODUCTION}

This paper deals with a teaching experience involving nursing consultation for people with diabetes mellitus (DM), treated at a Family Health Unit (USF). This experiment was developed on the basis of the problem-based learning methodology, in order to promote the learning and resignification of this type of nursing via experienced reality.

The health situation in Brazil combines accelerated demographic and epidemiological transitions, resulting in a triple burden: infectious and parasitic diseases yet to be overcome, growth of external causes and a considerable increase of chronic conditions $^{(1)}$. This scenario has direct implications for the public health system, whose responses have to be coherent with the needs of the population. Although the Unified Health System (SUS) is theoretically oriented to the promotion of health and integral care, there remains the difficulty of surpassing a fragmented model of health care, generally geared towards acute conditions. A dissonance between necessity and practice persists: treatment models conceived for acute conditions are ineffective when applied to for chronic health problems ${ }^{(2)}$.

Given the fact that chronic conditions, especially chronic noncommunicable diseases (NCDs), evolve slowly, are multifactorial and coexist with biological and sociocultural determinants, approaching them requires proactive, integrated, interdisciplinary responses as well as the protagonism of individuals, families and community ${ }^{(2)}$. Among NCDs, systemic arterial hypertension (SAH) and DM are serious public health problems in the country. Combined, they make up the first cause of mortality and hospitalizations in the SUS, and represent more than half of the primary diagnoses of people with chronic renal failure undergoing dialysis ${ }^{(3)}$.

When it comes to care for people suffering from DM, the nurse, as a social transformation agent, has to organize and operationalize his/her work process according to the Systematization of Nursing Care (SAE) methodology, as determined by the no. 358/2009 Resolution of the Federal Nursing Council (Cofen). In this context, the nursing consultation (NC) is an important practice, and must meet the health needs of users in an integral and effective way.

To this end, the academic space has to promote the construction of the knowledge necessary for the formation of a generalist nurse, based on scientific, intellectual and ethical rigor. The 2001 National Curriculum Guidelines (DCN) for undergraduate nursing courses state that the nurse must have knowledge and act upon the most prevalent health problems of the national epidemiological profile, with an emphasis on the epidemiology's region of action and determinant biopsychosocial factors.

The construction of the necessary skills for doing so occurs with the insertion of the academic in the community, in activities that favor the integration of teaching and health care services, collaborating to a constant reflection on the praxis of nursing. To realize this, active and problem-based learning methodologies, aiming at a more effective approximation of nursing student and community, may play a pivotal role, together with the creation of flexible pedagogical projects and the implementation of interdisciplinary practices ${ }^{(4)}$.

It is necessary to constantly rethink the training of nurses in order to achieve higher levels of intellectual, social and ethical performance. For this, the problem-based learning methodology has as its starting point real problems and situations, which students might experience in professional practice. Thus, the student is provided with living elements of learning ${ }^{(5)}$.

\section{OBJECTIVE}

To describe the experience of employing problem-based learning to teach the practice of nursing consultations in support of people with diabetes mellitus, in the context of a Family Health Unit (USF).

\section{METHOD}

This is the report of a teaching experience with the problembased learning methodology $y^{(5)}$, in the context of the Collective Health Nursing IV course given at a community university located in the central-western region of the state of Rio Grande do Sul (RS). The subject is part of the seventh semester of the undergraduate nursing course.

The field activity of the course was carried out during the first half of 2016, in a USF that provides healthcare for about 3110 people. Among these, $84(2.7 \%)$ were registered with a diagnosis of DM. It is also worth noting that the specific USF in which the study was carried out is a Laboratory Unit of Basic Care Planning, a part of the National Program for Improving Access and Quality of Basic Care. This is why it serves as a basis for practical classes of the nursing course.

Care for people diagnosed with DM was identified by Basic Care Planning as an emergent need in this specific USF. Given this situation, the university sought to carry out actions that would contribute to strengthen the USF's service, as well as improve the training process when it comes to care for people with chronic NCDs.

A four-pronged activity was planned. In the first stage, the proposal was presented by the course's teacher to the USF's staff, in order to receive professional contributions and adjustments in its execution. The second stage occurred in the classroom, after a discussion on the Model of Care For Chronic Conditions, the Health Care Network (RAS), and the epidemiological profile 
of the region to which the municipality belongs. Students were then instigated to apply the Systematization of Nursing Care (SAE) methodology to a scenario related to a hypothetical DM patient. The theoretical basis of the activity were the number 35 and 36 ${ }^{(1)}$ Basic Care Notebooks (Cadernos de Atenção Básica, CAB) provided by the Ministry of Health (MS). This material deals with strategies for the care of people with chronic diseases such as DM.

In the third stage, carried out inside the USF, the class was divided in pairs to implement SAE in the care of people suffering from DM. The SAE, which allows for the operationalization of the nursing process, followed five stages: history, diagnosis, planning, implementation and evaluation. The necessary nursing history information was collected based on the recommendations from $\mathrm{CAB}$ no. $36^{(1)}$, which includes aspects such as identification, family and personal history, current complaints, history of diagnoses and previous treatment, self-perception of the disease, treatment and self-care, medications in use, lifestyle habits and identification of risk factors, in the context of the user's home and family environment. At that time, nursing consultations at the USF were scheduled, in order to perform physical examinations and request laboratory tests.

From the nursing history, the physical examination and the results of the laboratory tests, nursing diagnoses and a care plan were elaborated (after discussions with the teacher and the USF's team). Subsequently, meetings were scheduled for sharing the obtained information with the DM patient. These meetings took place either in the DM patient's residence or in the USF. In the fourth stage, the academics performed the complete recording of the SAE-obtained data in the users' electronic medical record (e-SUS). For this task, two guidelines were employed: Subjective, Objective, Analysis and Planning (SOAP) and International Classification for Nursing Practice $\left(\mathrm{CIPE}^{\circledR}\right)$. This facilitated the communication among professionals and the retrieval of clinical data.

Finally, after an average of twenty days between the first and last contact of the pairs of students with the people suffering from DM (eighteen users in total), the learning process was evaluated in the face of the experiences of nursing students, teachers and staff of the health unit ${ }^{(5)}$. Perceptions about the experience are reported below.

\section{Partnership between staff and academia: uniting efforts to care and learn}

The proposal to carry out the educational action involving care for people with DM, in addition to being provisioned in the legal framework of the public health system which provides for the training of SUS human resources-was supported by the USF staff, since they allowed academics and students to enter the routine of their daily work. Such support allowed undergraduates to actually contribute in fulfilling the service's demand, which provided them with theoretical and practical experiences in the care of people with DM.

Before the beginning of the semester, there was a meeting between the university and the USF staff for planning the proposed activity. Initially the staff chose a micro-area of the territory to serve as a basis for the experience, indicating participants. Afterwards, the names and addresses of the users were made available, as well as the authorization to request laboratory exams; the material resources for the physical examinations available in the unit were identified, and the nurse's care schedule was organized, with one hour allocated to each visit.

Regarding these material resources, the university covered costs for the purchase of materials not provided by the Health Ministry, such as a $128-\mathrm{Hz}$ tuning fork and a 10-g monofilament for assessing the loss of protective sensibility of the feet ${ }^{(1)}$. The deadline for delivering results of examinations was agreed upon with the laboratory of clinical analyzes associated with the Municipal Health Department. Thus, the collection and receipt of the results of the laboratory tests occurred during the period in which the students were still working in the USF. This was to make a complete clinical evaluation possible ${ }^{(1)}$. Through these measures, a dialogue between actors belonging to the university and the health service was established, serving as a basis for strengthening partnerships and, therefore, improving the academic formation and the quality of the assistance provided, in a demonstration of the importance of this type of integration.

The successful inclusion of university academics and students in the health staff corroborated the proposal of the teaching/ health service integration, which requires a clarity of objectives able to unify the actions of managers, teachers, students and health service workers. One of the issues interfering with the full realization of this integration is the need for a collective appropriation, by the different agents of the teaching/health service integration, of the appropriate theoretical framework. This framework is necessary to guide both health education and health care, enabling the structuring of services able to perform both tasks ${ }^{(6)}$.

In addition to acquiring a common theoretical knowledge, the involved parties must value a kind of training focused on a construction of knowledge arising from actual experiences. In this sense, we emphasize that the approximation between theory and practice demands from future professionals a critical view, in order to approach real, practical problems found in the dayto-day of health services ${ }^{(7)}$. In order to build this critical view, we have as a tool the methodology of problem-based learning, which has a recognized capacity for training professionals of different specialties and competences, offering experimental opportunities for articulating knowledge, skills and attitudes fundamental to the training of a generalist nurse.

This partnership contributed to the implementation of nursing consultation for people with DM, and to establish a programmed agenda ensuring the fulfillment of essential attributes of Primary Health Care, such as longitudinality and completeness of care for patients with chronic illness, among others. Chronic diseases require permanent health care, so as to prevent possible complications of disease progression. It should be stressed that, in addition to the partnership itself, the experience applied the methodology of problem-based learning to the context of a practical teaching activity, allowing for the understanding of the important role nurses have in Primary Health Care, by contributing to integral health care in local nodes of the health care network.

The experience convinced us of the relevance of a professional formation of nurses in dialogue with the reality of health services and the population. In addition, proactive health promotion, 
as well as the systematic improvement of health care, were emphasized as inherent advances of the teaching/health service integration. Thus, it is necessary to train generalist nurses who are able to act according to a region's epidemiological, social and cultural profile, considering the importance of local health clinics to the population.

Contributions to nursing practice in Primary Health Care

Based on the assumption that nursing consultation is capable of producing positive effects on DM control and promote improvements in quality of life, this experience involved the active search for people with DM, with visits being made to their residences. The experiment had nursing consultation as an object precisely because it allowed the biomedical perspective to be surpassed, so the individual in his/her life context can be considered an able participant of the care process. The insertion of health care professionals in the patient's daily life aids in the identification of factors capable of contributing to management of the disease ${ }^{(8)}$.

The retrieval of the nursing history at the users' homes was decisive for the development of the proposal, since this space has a singular character for the dialogue between users and patients. This allowed the academics to get to know the in loco context of people's lives, entering a dialogue to establish the links necessary for an effective therapeutic relationship, focused on the demands of the person suffering from DM.

At home, the emphasis was on effective communication and sensitive listening ${ }^{(2)}$, through which academics, following the script proposed by $\mathrm{MS}^{(1)}$, identified socioeconomic data, occupation, housing and work conditions, schooling, leisure options, religion, family network, vulnerabilities and potential for self-care, taking into account the influence that social determinants have on the health status of the person suffering from DM and also on important aspects of the therapeutic plan.

After retrieval of the nursing history, users were invited to go to the USF at a scheduled date and perform physical examinations; this meeting was considered a nursing consultation, even though users were aware that the activity at home was also part of the process. The meeting at the USF was designed to make the user aware of the nurse's clinical assistance.

At the USF, the students, accompanied by the teaching nurse, conducted the user to the nursing office. In view of this reception, we observed that the first contact at home was a positive resource for the establishment of a bond: users arrived well-disposed, at the scheduled time, verbally expressing their curiosity to know "how this nursing consultation thing works."

For an effective practice to be developed, it is important for users express themselves and for their singularity to be valued. This way, a mutual responsibility for the care process can be established ${ }^{(9)}$. In this sense, meetings in the nursing office space took place in observance of ethical conduct and qualified listening practices, in order to guarantee a well-executed collection of data for the analysis of each case. Qualified listening has to be reiterated as an important therapeutic resource to strengthen the bonds between users and health professional, and to identify aspects that require intervention in the short, medium and long term.
After receiving information pertinent to the nursing consultation, users underwent physical examination, following the protocol prosed in $\mathrm{CAB}$ no. 36: verification of height, weight, waist circumference and $\mathrm{BMI}$, heart and respiratory rate, blood pressure, oral cavity examination, cardiopulmonary auscultation, assessment of skin integrity, turgor, coloration and staining ${ }^{(1)}$. Special attention was given to the lower limbs: nails, pain, edema, pedal pulses and lesions, joints (flexibility, capacity of extension, limitations of mobility, edema) and thorough physical examination of the feet, with a view to neurological evaluation.

Laboratory tests were also requested at this stage, especially for those who had not been evaluated for more than six months. The requested tests followed the MS protocol for follow-up and stratification of metabolic control, including: complete blood count, fasting glycemia, glycated hemoglobin, total cholesterol, $\mathrm{HDL}$, triglycerides, urea, creatinine and qualitative urine test $\mathrm{t}^{(1)}$.

At this stage, academics had the opportunity to improve knowledge, skills and attitudes necessary to perform the physical examination of people with DM, in addition to perceiving the importance given by the user to the nursing consultation, since most of them said they had never received this type of care. As such, one can perceive the methodology of problem-based learning as an advance for teaching based on clinical practice, scientific knowledge, sensitive care and social recognition of the profession.

It is up to the nurse to stimulate the autonomy of the person suffering from DM, emphasizing health education as a technology for the promotion of care and prevention of diseases, focused on the protagonism of the person who has to live with the chronic illness, in a form of shared care. From this perspective, a person with DM is expected to recognize the risk factors and learn to overcome problems, assuming co-responsibility for their own care $^{(1)}$. Thus, the nursing consultation, performed according to the MS protocols, enabled qualified, safe nursing care, with the integration of evidence that guides the protocols, the use of the SAE methodology and the advancement of a kind of training rooted in problem-based learning.

In the interval between performing the physical examination and analyzing the results of the laboratory tests, the students read, listed the obtained nursing diagnoses and formulated a care plan based on the collected data. This required a deeper understanding of the theoretical contributions of the CIPE ${ }^{\circledR}$ and of DM care stragies in Primary Health Care, as well as the study of the Framingham Score to calculate cardiovascular risks, which took place in the USF on the basis of reading theoretical references in the area of nursing (as well as guidelines from MS), and the exchange of experiences between teachers, students and professionals of the health team.

This knowledge allowed the development of skills and attitudes fundamental for clinical reasoning; as such, they were intervening factors in determining responses and decisions in the different stages of the teaching proposal. This result is in line with the idea that stimulating clinical thinking from the beginning of the student's academic activities can contribute to the formation of professionals with greater resourcefulness, in terms of skills essential for good performance in professional and daily-life decisions ${ }^{(10)}$. The experience with problem-based learning motivated academics to seek learning and, therefore, to intervene in reality, strengthening the pedagogical process. 
The intervention occurred through the following nursing diagnoses:

Chart 1 - CIPE ${ }^{\circledR}$-based list of diagnoses, Rio Grande do Sul, Brazil, 2017

\begin{tabular}{|l|l|l|}
\hline \multicolumn{1}{|c|}{$\begin{array}{c}\text { Favorable } \\
\text { diagnoses }\end{array}$} & \multicolumn{2}{|c|}{ Diagnoses requiring further attention } \\
\hline $\begin{array}{l}\text { Adequate } \\
\text { knowledge about } \\
\text { the medication }\end{array}$ & $\begin{array}{l}\text { Inadequate knowledge } \\
\text { about the medication }\end{array}$ & Fatigue \\
\hline $\begin{array}{l}\text { Sensitivity } \\
\text { preserved in lower } \\
\text { limbs }\end{array}$ & $\begin{array}{l}\text { Decreased sensitivity in } \\
\text { the lower limbs }\end{array}$ & Impaired walking \\
\hline $\begin{array}{l}\text { Adequate } \\
\text { knowledge about } \\
\text { diabetes mellitus }\end{array}$ & $\begin{array}{l}\text { Inadequate knowledge } \\
\text { about diabetes mellitus }\end{array}$ & $\begin{array}{l}\text { Inadequate } \\
\text { knowledge about } \\
\text { exercises }\end{array}$ \\
\hline Effective rest & Impaired nutrition & $\begin{array}{l}\text { Obesity or } \\
\text { overweight }\end{array}$ \\
\hline $\begin{array}{l}\text { Skin integrity } \\
\text { preserved }\end{array}$ & Impaired skin integrity & $\begin{array}{l}\text { Risk of diabetic } \\
\text { foot }\end{array}$ \\
\hline $\begin{array}{l}\text { Temporal and } \\
\text { spatial awareness } \\
\text { preserved }\end{array}$ & $\begin{array}{l}\text { Inadequate self-care } \\
\text { relative to feeding, } \\
\text { treatment protocol and } \\
\text { feet }\end{array}$ & $\begin{array}{l}\text { Edema in the } \\
\text { lower limbs }\end{array}$ \\
\hline $\begin{array}{l}\text { Acceptance of } \\
\text { diabetes with } \\
\text { positive self-image }\end{array}$ & $\begin{array}{l}\text { Irregular exercise } \\
\text { practice }\end{array}$ & Hyperglicemia \\
\hline
\end{tabular}

Of the eighteen participants, two were identified as having high cardiovascular risk, with a $30 \%$ or more chance of presenting a coronary event, as well as amputation, in the next ten years. Considering this issue and the diagnoses and the results of the laboratory tests (marked dyslipidemia and glycated hemoglobin above the goal established for the user being treated with oral antiglucamy), the cases were discussed with the staff's physician, who introduced insulin in the treatment. At the same time, the staff directed users to health services of the secondary care level, based on the perspective of interprofessional work, organized according to the framework of the Health Care Network.

In view of this process, the individual care plan was presented and discussed with the team and with the users, in order to guarantee a collaborative practice. This encourages users to implement lifestyle changes, through participation in health groups promoted by the USF in partnership with community groups (community associations, churches, social assistance centers); it also improves attendance at consultations scheduled with nurses and service doctors.

The execution of the teaching proposal was formally recorded in the users' electronic records (e-SUS AB). In this system, the "SOAP" is suggested as a means of data recording: ' $\mathrm{S}$ ' stands for Subjective, concerning data related to medical history; ' $\mathrm{O}$ ' stands for Objective, concerning data collected in the physical examination; ' $\mathrm{A}$ ' stands for Assessment, during which the nursing diagnoses were chosen; ' $\mathrm{P}$ ' stands for Plan, referring to the nursing interventions proposed for each user/family. Alongside other moments of the formative evaluation, data recording in the e-SUS represented an opportunity to discuss the experience with the students and reflect on the nursing praxis. At that moment, frailties still present in the training were identified, related, for example, to knowledge on pharmacology, laboratory tests, anatomy and semiology. There was a clear need to minimize them through feasible and effective strategies, such as problem-based learning, that potentiate meaningful learning.

Teaching proposals instituted to assist people suffering from DM contribute to the control of signs and symptoms, helping them cope with disabilities and adapt to the social and psychological changes resulting from the illness ${ }^{(1)}$. In addition, such proposals enable people to learn how to live with and manage the disease in the face of everyday situations, sensitizing them about the need for behavioral changes along the course of the illness.

It should be noted that the evaluation of the suggested and implemented interventions has been carried out by the unit's nurse and by other academics (who took part in the USF during subsequent semesters). This demonstrates a respect for the necessary longitudinality in the care of people with chronic diseases, since chronic NCD patients need permanent and continuous support to deal with the different issues that permeate their condition. In addition, in this context the nurse can be perceived as an organizer of care among the different members of the health teams, obtaining information, discussing it with peers and acting in the implementation of strategies that meet the singularities of the one who is cared for.

Regarding the limits encountered throughout the experience, it is necessary to point out that in some cases the available nursing consultation dates did not coincide with the user's availability, making it necessary to reschedule it. This limit of availability can perhaps be surpassed during the supervised curricular stage, when students intervene more actively in relation to both staff and users.

As to contributions from this research, we highlight: the training of nurses who are sensitized and qualified to work in Primary Health Care services, with knowledge built around policies of health, management and clinical practice; the qualification of nursing care for users with DM, and the description of an experience for the implementation of teaching/health service integration. Teaching-wise, we emphasize the importance of problem-based learning for developing and qualifying the nursing discipline. This experience can be replicated in other realities, favoring the formation of professionals focused on clinical practice and epidemiology, as well as bringing forth cultural and social aspects that permeate the subjects' daily lives. We believe that the report of this experience will contribute to inspire the academic community and health professionals to reassess the importance of the nursing practice for Primary Health Care.

\section{FINAL CONSIDERATIONS}

This teaching experience allowed for the reorganization of nursing care for people with DM in an USF of the Primary Health Care system, outlining a model for the integration between 
teaching, health service and user, as well providing students with meaningful learning, i.e., a live relationship between theory and practice.

For the academic community—both students and teachers_it was a unique experience, impossible to be realized in the constrained space of the classroom. Daily life became the object of learning, and the students had to deal not only with specific problems of an education in nursing, but also issues of interdisciplinarity and communication within the Primary Health Care network.

For the users, the nursing consultations meant undivided attention to their chronic condition, helping them identify their potentialities and difficulties, as well as arriving at proposals for actions consistent with experienced reality. We believe that with this experience, new ways of caring can be delineated, in keeping with the country's sociocultural and epidemiological profile, and taking into account the clinical demands imposed by non-communicable chronic diseases.

Finally, we emphasize the potential of problem-based learning, involving theoretical and practical activities that strengthen the training of nursing students. Given that it allows undergraduates to experience real-life situations, we hope that this process, with its innovations, will influence the trajectories of today's students-tomorrow's health professionals-in health care and the SUS.

\section{REFERENCES}

1. Brasil. Ministério da Saúde. Secretaria de Atenção à Saúde. Departamento de Atenção Básica. Estratégias para o cuidado da pessoa com doença crônica: diabetes mellitus [Internet]. Brasília: Ministério da Saúde; 2013[cited 2018 Aug 15];(col. 35-36). Available from: http://189.28.128.100/dab/docs/portaldab/publicacoes/caderno_36.pdf

2. Mendes, EV. O cuidado das condições crônicas na atenção primária à saúde: o imperativo da consolidação da estratégia da saúde da família [Internet]. Brasília: Organização Pan-Americana da Saúde; 2012[cited 2018 Aug 15]. Available from: http://bvsms.saude. gov.br/bvs/publicacoes/cuidado_condicoes_atencao_primaria_saude.pdf

3. Schmidt MI, Duncan BB, Silva GA, Menezes AM, Monteiro CA, Barreto SM, et al. Chronic non-communicable diseases in Brazil: burden and current challenges. J Lancet [Internet]. 2011[cited 2018 Aug 15];377(9781):1949-61. Available from: https://www. thelancet.com/journals/lancet/article/PIIS0140-6736(11)60135-9/fulltext

4. Gentil DF, Abilio ES, Cordeiro MJJA. [Limits and curriculum challenges in the formation of professionals to act in the unified health system]. Interfaces da Educ [Internet]. 2015[cited 2018 Aug 15];6(17):77-96. Available from: http://periodicosonline.uems.br/index. php/interfaces/article/view/747/688 Portuguese.

5. Berbel NAN. [Problematization methodology: answer from lessons obtained through practice]. Semina [Internet]. 2014[cited 2018 Aug 15];35(2):61-76. Available from: http://www.uel.br/revistas/uel/index.php/seminasoc/article/view/18193/16500. Portuguese.

6. Brehmer LCF, Ramos FRS. [Experiences of teaching-service integration in the process of professional development in health: na integrative review]. Rev Eletr Enferm [Internet]. 2014[cited 2018 Aug 15];16(1):228-37. Available from: https://revistas.ufg.br/fen/ article/view/20132/16462 Portuguese.

7. Mesquita KCM, Meneses RMV, Ramos DKR. [Active teaching/learning methodologies: dificulties faced by the faculty of na nursing course]. Trab Educ Saúde [Internet]. 2016[cited 2018 Aug 15];14(2):473-86. Available from: http://www.scielo.br/pdf/tes/v14n2/16781007-tes-1981-7746-sip00114.pdf Portuguese.

8. Silva TFA, Rodrigues JEG, Silva APSM, Barros MAR, Felipe GF, Machado ALG. [Nursing consultation to persons with diabetes mellitus in primary care]. Rev Mineira Enferm [Internet]. 2014[cited 2018 Aug 15];18(3):710-6. Available from: http://www.reme. org.br/artigo/detalhes/957 Portuguese.

9. Santos FPA, Acioli S, Rodrigues VP, Machado JC, Souza MS, Couto TA. Nurse care practices in the Family Health Strategy. Rev Bras Enferm [Internet]. 2016[cited 2018 Aug 15];69(6):1060-7. Available from: http://www.scielo.br/pdf/reben/v69n6/en_00347167-reben-69-06-1124.pdf

10. Carvalho EC, Oliveira-Kumakura ARS, Morais SCRV. Clinical reasoning in nursing: teaching strategies and assessment tools. Rev Bras Enferm [Internet]. 2017[cited 2018 Aug 15];70(3):662-8. Available from: http://www.scielo.br/pdf/reben/v70n3/0034-7167reben-70-03-0662.pdf 